\title{
Decentralize power sharing control strategy in islanded microgrids
}

\author{
Mubashir Hayat Khan, Shamsul Aizam Zulkifli, Erum Pathan, Elhassan Garba, \\ Ronald Jackson, Haider Arshad \\ Department of Electrical Power Engineering, Faculty of Electrical and Electronics Engineering, \\ Universiti Tun Husein Onn Malaysia, Malaysia
}

\section{Article Info}

\section{Article history:}

Received Feb 5, 2020

Revised Apr 6, 2020

Accepted Apr 20, 2020

\section{Keywords:}

Decentralized control

Distributed generation

Power sharing

$\mathrm{P}-\omega$ droop

Q-V droop

\begin{abstract}
Droop control technique is one of the renowned techniques which does not need any communication connection between distibuted generations (DG), hence the cost, as well as the reliability of the microgrid (MG) system can be reduced. MG is operated in two modes as their functionality and structure is concern. These are the grid connected or islanded (stand-alone) mode. DGs operating values may have different ratings of voltage, power and line impedance. The power sharing in these operatng conditions is not shared equally by all DGs connected in the system and also during load changes conditions power sharing accuracy is difficult to achieve. In this paper, a droop power control is used to balance the power sharing in islanded mode. As from the results, the active power sharing is equally shared from all DGs connected in the microgrid system. However, reactive power sharing accuracy always disturbed when there is impedance mismatch among the different DG feeders. The accuracy is done by monitoring the effects when load changes for low load to high load or vice versa. The proportional integral (PI) controller has been used to minimize the reactive power errors. At the end, the power droop is capable to share power accurately and results prove the stability and reliability of the proposed technique.
\end{abstract}

Copyright (C) 2020 Institute of Advanced Engineering and Science. All rights reserved.

\section{Corresponding Author:}

Shamsul Aizam Zulkifli,

Faculty of Electrical and Electronics Engineering,

Universiti Tun Husein Onn Malaysia, Batu Pahat, Johor, Malaysia

Email: aizam@uthm.edu.my

\section{INTRODUCTION}

Renewable energy sources like solar, bio-gases and many more are being widely used for the production of electricity. Due to higher fuel cost and high carbon emission, the conventional power generation is losing the interest to be applied. Moreover, the modern grid structure is moving towards decentralized structure which is more stable and more reliable. A distibuted generation (DG) can operate as islanded mode or when the DG is connected to the existing grid, it is known as grid connected mode. As compared to the grid connected, islanded mode of operation facing more power control issues $[1,2]$ especially on power sharing. Two types of the control that been used for MG controsl are known as communication based or non-communication based or droop control. The most commonly droop controls are P- $\omega$ (real power-frequency) and Q-V (reactive power-voltage) techiniques for accurate power sharing. P- $\omega$ droop is effective in order to share the real power in MG system with different rated DGs power are applied, but for Q-V droop control, various stability issues are there which are mainly;

a) It is harder to share power equally when DG inverters are connected together at the point of connection in the parallel connected DG inverter based microgrid system.

b) Local loads are not shared equally by all DGs connected in the system.

c) Line impedance effects because conventional droop control use an assumption of pure resistive or pure inductive output impedance that is not happened normally in real situations [3-7]. 
In islanded MG, a poor power sharing may lead the system towards instability in voltage, frequency and as well as the harmonic distortion. So, reactive power-voltage control technique needs to be investigated deeply to overcome aforementioned issues. Droop control has some limitations, and many literatures have improved droop control techniques to mitigate these droop limitations. In [8-10], common bus voltage and local voltage bus difference is utilized to cover up the Q-V output voltage but unfortunately the common bus utilized in this technique has practically unavoidable issues. Real time data calculation is proposed in [11-13] when the local loads are connect to bus system, although this technique improves power sharing but make this technique practically unstable. For heavy loads which have been explained in [14-16], conventional droop slope has been increased to mitigate the droop issues regarding power sharing.

For reactive power sharing, a technique using virtual impedance concept has been developed in [17-19]. The working principle is to compensate the output impedance of the DGs. Authors added an extra controller that has to estimate the output voltage [20]. Because of the unavailability of the real time data variation in impedance, the DGs connect in the same network where accurate power sharing could not be guaranteed [20-22]. Q-V droop error has been investigated in [23] and authors proposed a novel technique that corrects the gain droop error according to the variation of the operating points of DG units. By computing all the disturbances of the real power where have been used in [24-27] to share an accurate power. Moreover, in this technique a low band communication has been used to initiate the signals from secondary controller by using the integral terms in order to manage the disturbances. As compared to communication techniques, for initializing an error signal for communication link, a slow response is the main issue of the approach. Information transmission may fail during operation and entire system may stop. Reliability of the system is not guaranteed in this approach. Another serious problem of the technique is to maintain stability during load changes as stated in [27]. The output impedance mismatch among different DG units are significantly increased the errors in reactive power sharing precision as per the capacity of DGs connected in a network [28].

This paper presents a power droop control for accurate power sharing which is arranged as: Introduction is given in Section 1. Modelling of parallel connected DG inverters is depicted in Section 2. Section 3 presents the parallel connected Distributed Generation inverter's control strategy. Section 4 presents the simulation results discussion and case studies. At the end in Section 5 conclusion of this research is presented.

\section{MODELLING OF PARALLEL CONNECTED DG INVERTERS}

Schematic diagram of MG consisting of 3 DG units is shown in Figure 1. DG inverters are interfaced with common $\mathrm{AC}$ bus through a specific feeder impedance. $\mathrm{LC}$ filter with the values $\mathrm{L}=6 \mathrm{mH}, \mathrm{C}=40 \mu \mathrm{F}$ are illustrated in Table 1. To maintain asymmetrical network certain local loads are also added to the network.

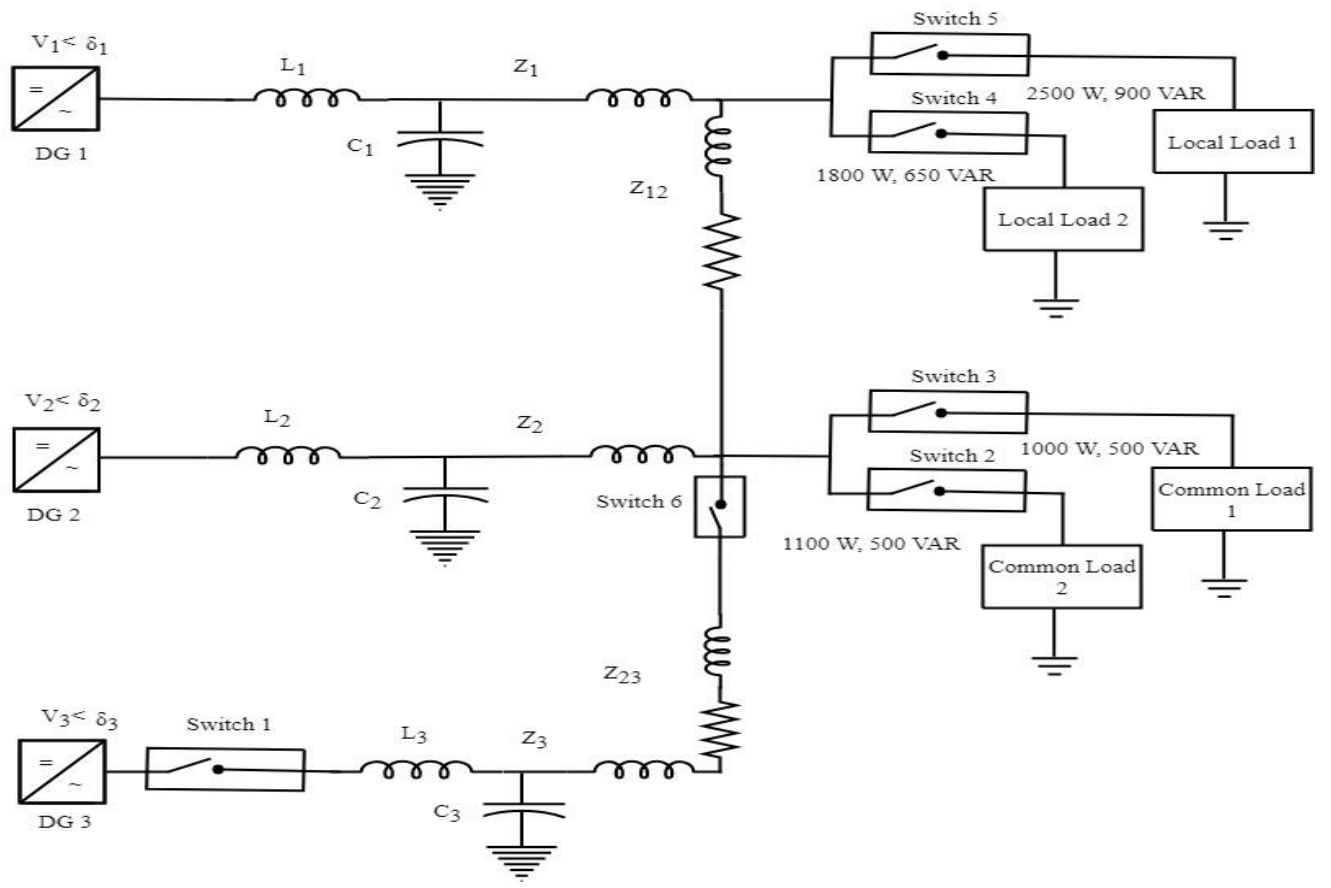

Figure 1. Micro-grid system under test 
Table 1. Parameters of MG under consideration

\begin{tabular}{cll}
\hline \multicolumn{1}{c}{ Parameter } & \multicolumn{2}{c}{ Values } \\
\hline & DG ratings & $\mathrm{DG} 1=\mathrm{DG}=\mathrm{DG} 3=7 \mathrm{KVA}$ \\
& DC offset voltage & $400 \mathrm{~V}$ \\
& Nominal Voltage & $120 \mathrm{~V}$ \\
System Parameters & Feeder Impedances & $\mathrm{Z}_{1}=\mathrm{Z}_{2}=\mathrm{Z}_{3}=0.2+1.141 \mathrm{i} \Omega$ \\
& Inverter Filters parameters & $\mathrm{Z}_{12}=\mathrm{Z}_{23}=0.3+0.754 \mathrm{i} \Omega$ \\
& Sampling Period & $\mathrm{L}^{*} 10^{-6} \mathrm{~s}, \mathrm{C}=40 \mu \mathrm{F}$ \\
& Compensation Controller & $\mathrm{K}_{\mathrm{p}}=0.003, \mathrm{~K}_{\mathrm{i}}=0.0286$ \\
& Voltage Controller Gain & $\mathrm{K}_{\mathrm{p}}=0.3, \mathrm{~K}_{\mathrm{i}}=280.8$ \\
& Current Controller Gain & $\mathrm{K}_{0}=0.25$ \\
& Droop Coefficient of Voltage & $\mathrm{D}_{\mathrm{Q} 1}=\mathrm{D}_{\mathrm{Q} 2}=\mathrm{D}_{\mathrm{Q} 3}=0.00142$ \\
& Droop Coefficient of Frequency & $\mathrm{D}_{\mathrm{P} 1}=\mathrm{D}_{\mathrm{P} 2}=\mathrm{D}_{\mathrm{P} 3}=0.00124$ \\
\hline
\end{tabular}

Mainly, the generation of active and reactive power references are given by central controller, where a droop control technique is applied for power references. Conventional droop control mechanism follows the basic methodology of synchronous generator. Figures 2(a) and (b) show the relationship of real and reactive power droop strategies. Most used droop control techniques are categorized as; Real power-frequency droop control $(\mathrm{P}-\omega)$ and Reactive power-Voltage droop control $(\mathrm{Q}-\mathrm{V})$. Droop control slopes are given.

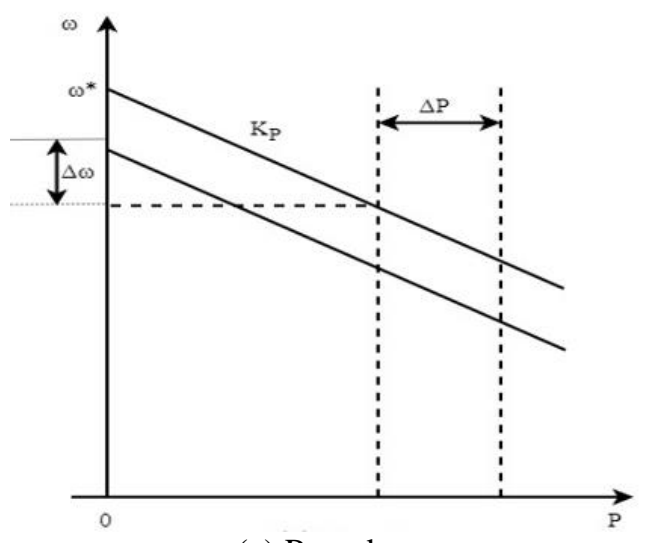

(a) P- $\omega$ dropp

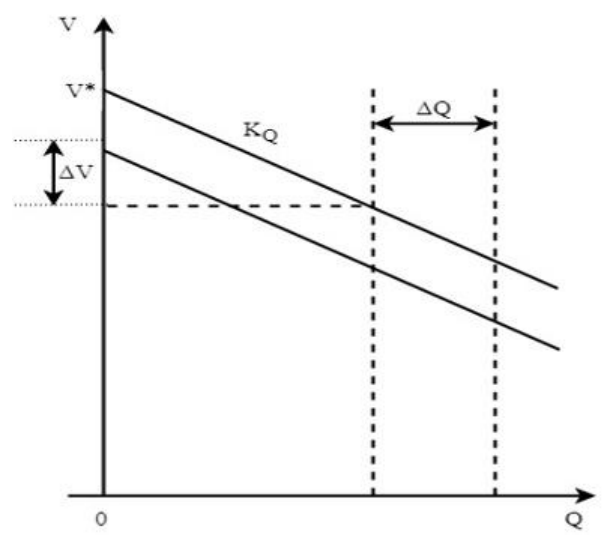

(b) Q-V droop

Figure 2. Droop concept6

When different DGs are operating in the microgrid, load sharing is not properly shared by each DG in the network. So, the voltage and frequency deviations occur in the system and it can be addressed by the droop control techniques. Frequency active power and voltage reactive power relationships given as;

$$
\begin{aligned}
& \omega=\omega_{o}-K_{p} P \\
& V=V_{o}-K_{Q} Q
\end{aligned}
$$

Where $K_{P}$ and $K_{Q}$ show the power, droop slopes for active and reactive power. The calculation for $K_{P}$ and $K_{Q}$ are given in as shown in (3) and (4) respectively.

$$
\begin{aligned}
K_{P} & =\frac{\omega_{\max }-\omega_{\min }}{P_{\max }} \\
K_{Q} & =\frac{V_{\max }-V_{\min }}{2 Q_{\max }}
\end{aligned}
$$

From the conventional droop control technique, an accurate active power sharing is attained by utilizing this technique but the accurate reactive power sharing cannot be achieved easily as mentioned in [29-31]. Power sharing errors can be calculated as; 


$$
\omega_{o}-\omega=K_{P} \cdot D_{P} P+D_{Q} Q
$$

From the (5) it is clear that if the droop coefficients $\left(D_{P}\right.$ and $\left.D_{Q}\right)$ are equal for all DG units connected in a network and also at the same time $\left(D_{P} P+D_{Q} Q\right)$ should also be equal for all of DG units connected in a network

\section{PARALLEL CONNECTED DISTRIBUTED GENERATION INVERTER CONTROL STRATEGY}

The aim of paper is focused on the implementation of reactive power sharing correction control technique. The flow chart for representation of the control technique is shown in Figure 3 . It is where the reactive power correction technique with start recognition topology for output voltage compensation is dependent on DC reference voltage. The output of the generated voltage is fed to inner loop control for power sharing accuracy in this control technique. The suggested technique based on the fact that, whenever there is a change at operating point of DGs units connected to a microgrid system, the accurate reactive power sharing is affected. Power sharing control is given in Figure 4 where reference $\mathrm{P}$ and $\mathrm{Q}$ are added to power calculations and than local based recognition topology is utilized for power compensation controller.

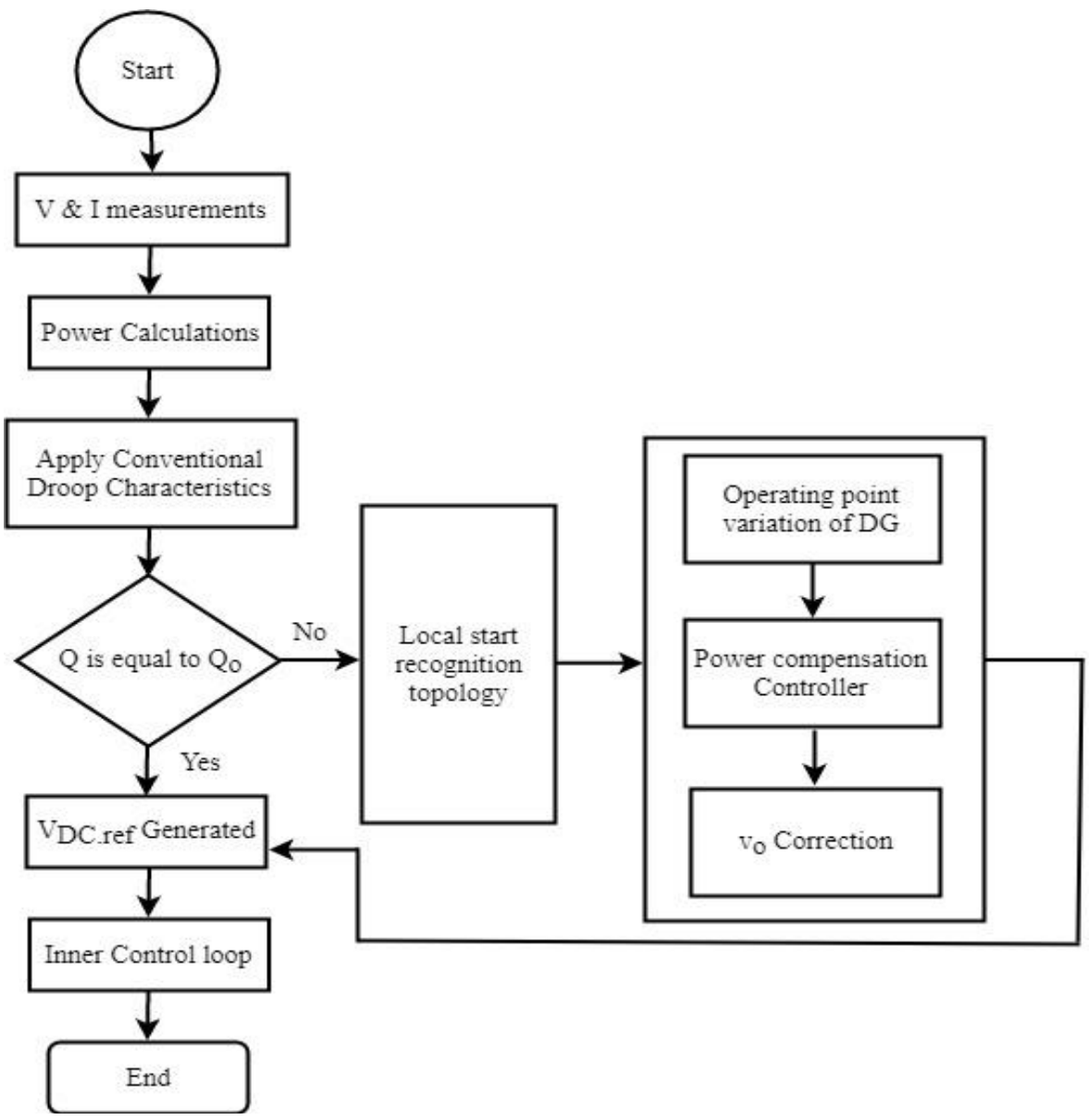

Figure 3. Flow chart of control technique

In this paper two steps are explained for the power sharing for modified compensation strategy.

a) At start, the droop control method is utilized.

b) In the second step at steady state, when $\mathrm{Q}$ is not equal to Qo than the power correction technique named as reactive power sharing method is employed.

For the first stage, the droop technique is implemented in order to share real and reactive power for only when the system is in steady state condition. Second stage, is locally recognition-based control technique. So, at this stage the reactive power is added in the system. The coupling between real and reactive power plays an important role in this stage that measures the reactive power sharing error. 
According to this strategy two general situations are created by referring to Figure 5; when the value of reactive power $\mathrm{Q}$ is less than $\mathrm{Q}_{\mathrm{o}}$ in any of the $\mathrm{DG}$ unit, it will be like $\left(\mathrm{D}_{\mathrm{P}} \mathrm{P}+\mathrm{D}_{\mathrm{Q}} \mathrm{Q}\right)$ values tends to be increase as given in (5). Therefore, an increase in $\left(\mathrm{D}_{\mathrm{P}} \mathrm{P}+\mathrm{D}_{\mathrm{Q}} \mathrm{Q}-\omega_{\mathrm{o}}\right)$, it will increase the frequency which ultimately decreases the active power $\mathrm{P}$. The difference of the values of $\mathrm{P}$ and $\mathrm{P}_{0}$ is than utilized in PI controller. A voltage equation is shown in (6)

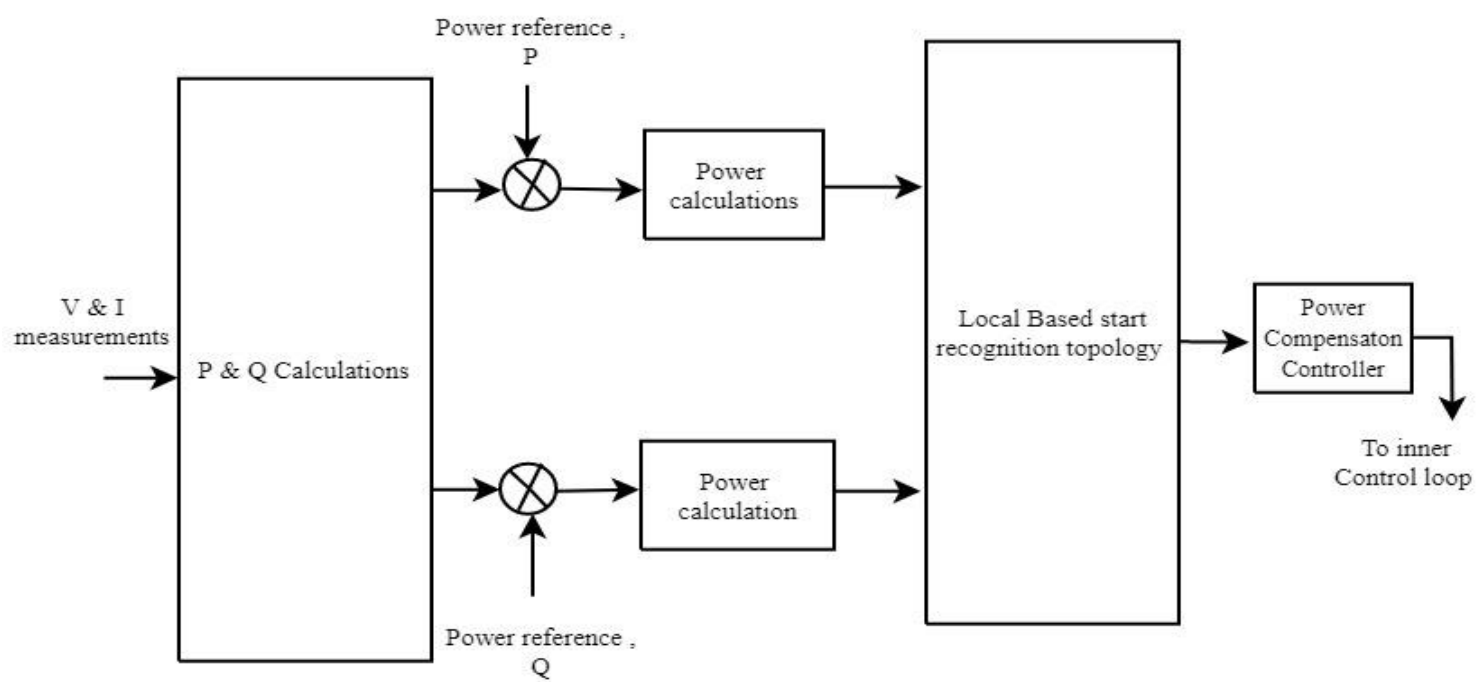

Figure 4. Power sharing correction control

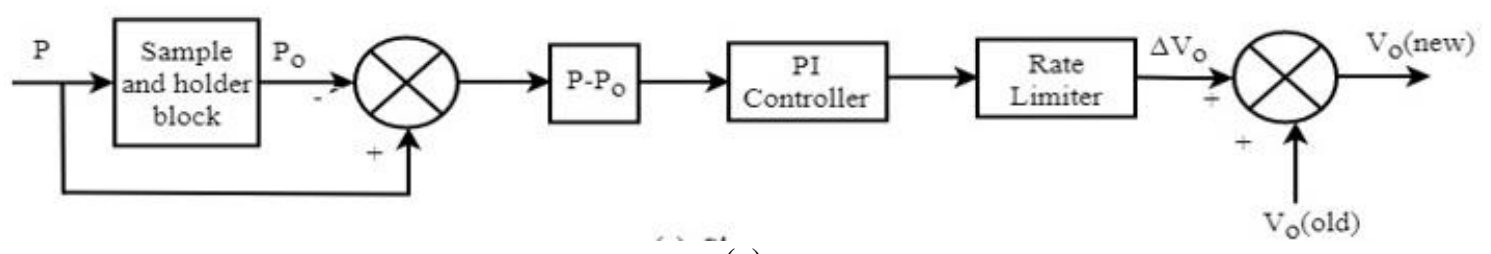

(a)

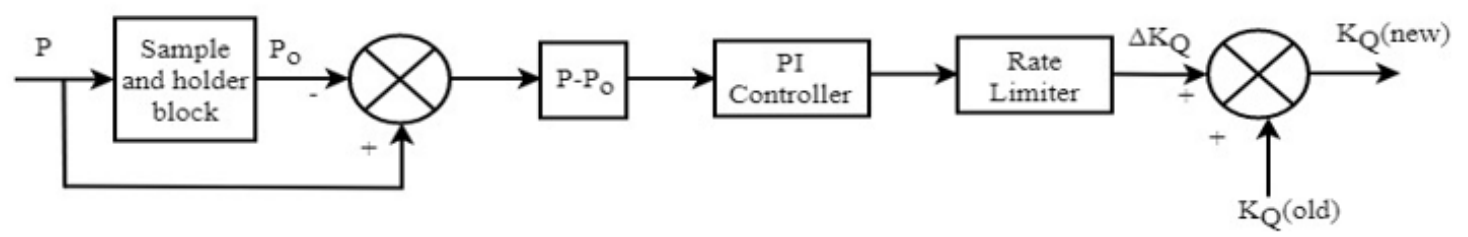

(b)

Figure 5. Correction in Q-V curve, (a) slope, (b) Y-intercept

$$
V=V_{o}-k_{Q} Q+\frac{I_{c}}{S} \cdot\left(P-P_{O}\right)
$$

where, $\mathrm{V}_{\mathrm{o}}, \mathrm{K}_{\mathrm{Q}}, \mathrm{Q}, \mathrm{Ic}, \mathrm{P}$ and $\mathrm{P}_{\mathrm{o}}$ are the output voltage, controller gain, reactive power, integral gain, active power and output active power respectively.

The error is compensated in such a way when the values of the voltage term as shown in Figure 6. Once, the compensation scheme is started to use (1) and (3) are been replaced by the (5) and (6). After passing through the PI controller, the entire values of $\mathrm{K}_{\mathrm{Q}}$ changed as given in 6 . Now the implementation of the rate limiter gives the accurate values of $\mathrm{K}_{\mathrm{Q}}$ and $V_{o}$ as per system requirements. When the values of $\mathrm{Q}$ and $\mathrm{Q}_{0}$ are the same, the active power will move towards its previous values which is given in the (5). The whole compensation carried out at primary level of MG control that is responsible for power sharing. As shown in Figure 6, the compensation scheme compensates the reactive power errors and new reference voltage will be generated. 


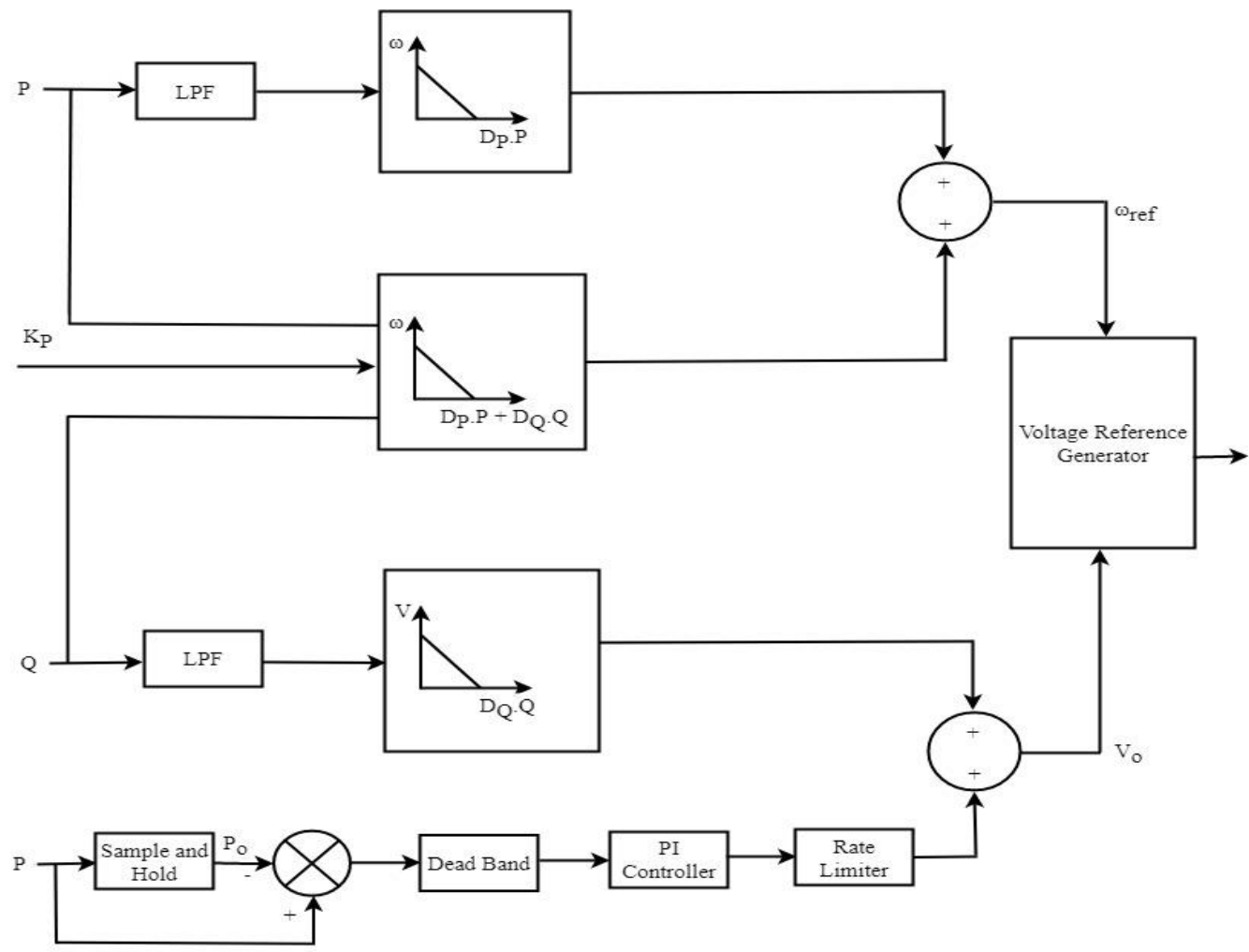

Figure 6. Reactive power correction strategy

\section{SIMULATION RESULTS, DISCUSSIONS AND CASE STUDIES}

Accurate reactive power sharing performance of the power droop method is been validated through MATLAB/Simulink and been categorized into three cases which are:

Case 1 : Accurate power sharing performance of inverter-based MG system by using the power droop method.

Case 2 : Analysis of the system response when increase or decrease in the connected local loads.

Case 3 : DG disconeted and reconected influence on the performance of neighbouring DGs.

\subsection{Case 1: accurate power sharing performance in the inverter based micro grid system by using the droop method}

MG system with two DGs which are $\mathrm{DG}_{1}$ and $\mathrm{DG}_{2}$, are connected in islanded mode with the local loads; load 1 (2500W, 900VAR) and Load 2 (1800W, 650VAR). Common load 1 and load 2 of (1100W, $500 \mathrm{VAR}$ ) are also connected to the system. At $\mathrm{t}=2 \mathrm{~s}$, the loads are increased to 2200W, 1000VAR. As there is an abrupt change in load conditions i.e. the load is greater than the two DGs capacity while $\mathrm{DG}_{3}$ is not connected to the grid. The third DG will start sharing at $t=4 \mathrm{~s}$ and the loads been shared equally in terms of power by each DG which are 733W, 333VAR as shown in Figures 7(a) and b). Figures 7(a), (b) and (c) demonstrates the active, reactive power sharing and voltage at point of connection respectively which shows that the power is sharing accurately with voltage busbar used, exactly in the allowed limit that is $114 \mathrm{~V}-116 \mathrm{~V}$ without any disturbance.

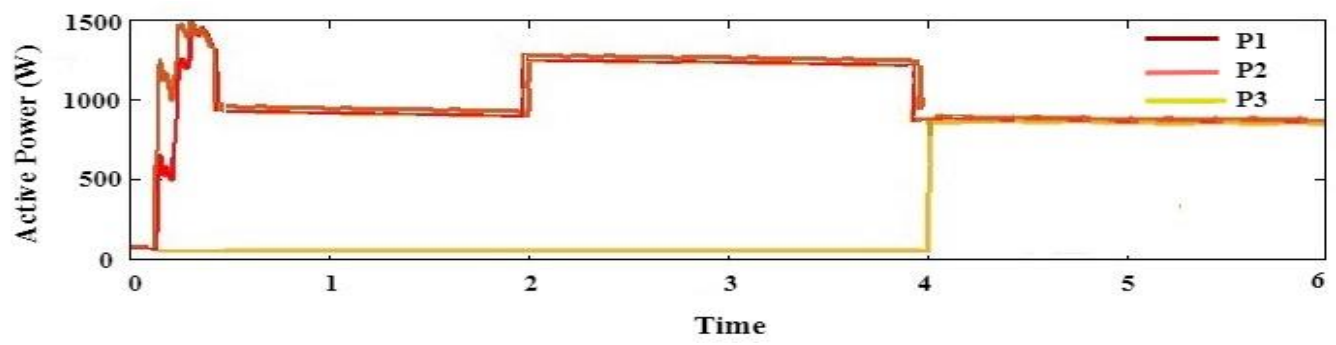

(a) Active power performance by utilizing the droop technique 


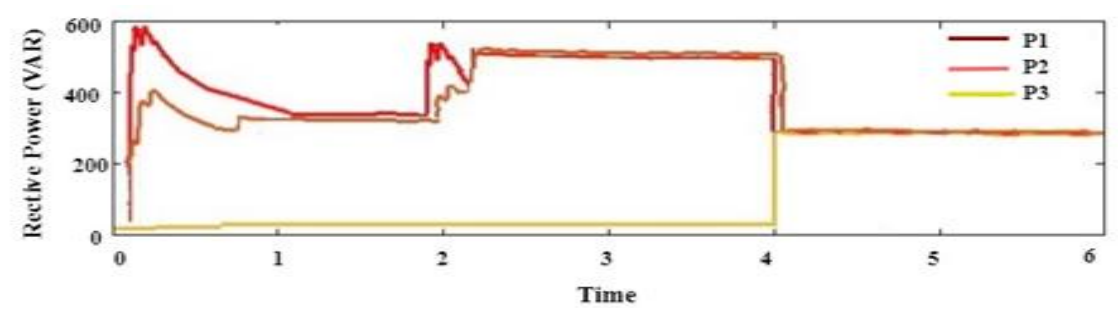

(b) reactive power performance by utilizing the droop technique

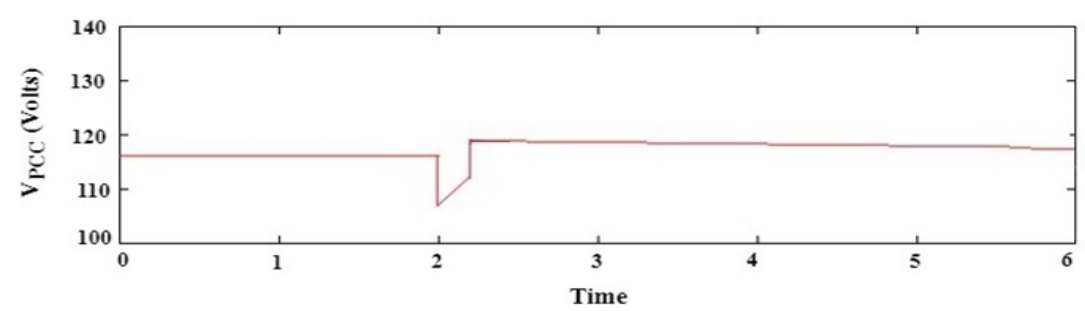

(c) voltage at point of common coupling

Figure 7. Power and voltages using power droop topology

\subsection{Case 2: analysis of the system response when sudden increase or decrease in the local load}

Figures 8 (a) and b) show the significant changes in the load sharing during the period $2 \mathrm{~s}$ to $4 \mathrm{~s}$. At the beginning, the load is connected to the network for local load operation. There are fluctuations due to the load variations and reactive power sharing is not accurate as can been seen in Figures 8(a) and b). Just after starting the simulation power sharing accuracy of $\mathrm{DG}_{1}, \mathrm{DG}_{2}$ and $\mathrm{DG}_{3}$ for connecting loads is not accurate which starts sattelling at $\mathrm{t}=1 \mathrm{~s}$. At $\mathrm{t}=2 \mathrm{~s}$, load at $\mathrm{DG}_{1}$ line is double to check the load sharing performance of all DGs connected in the microgrid system. Reactive power sharing starts after $t=4 \mathrm{~s}$ when both powers, the active and reactive powers are accurately shared, at $t=4 \mathrm{~s}$ the local load decreased after that the correction scheme properly starts. So, the Power sharing accuracy improved alot with the proposed correction sheme. Hence reactive power properly shares in three DGs microgrid system that is under test here.

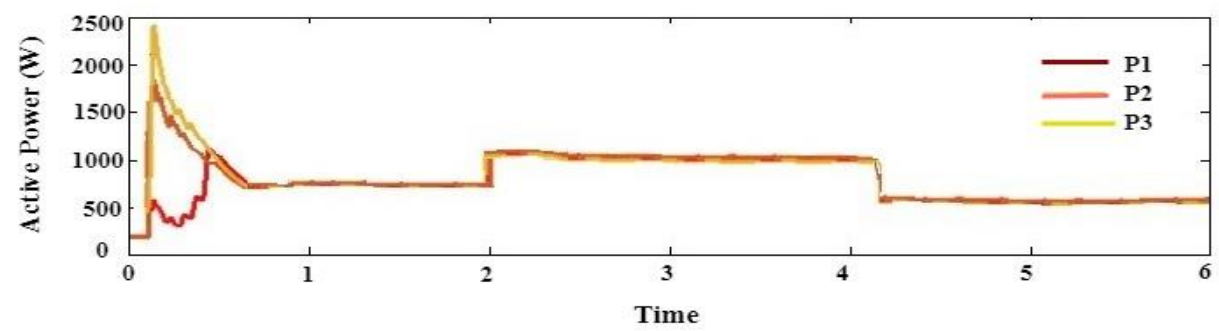

(a) active power at sudden change in connected load

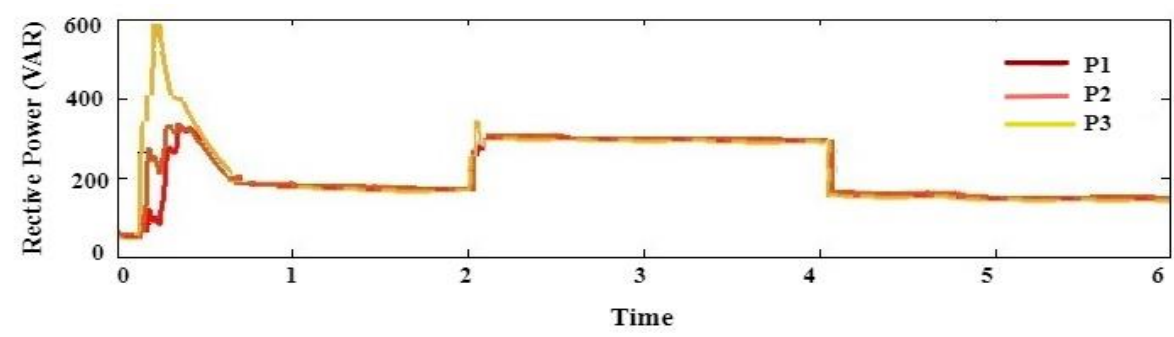

(b) reactive power at sudden change in connected load

Figure 8. Sharing of powers in case of load variations

\subsection{Case 3: DG disconeting and reconecting influence on the performance of neighboring DG}

It is conducted when all of the DGs are being connected to $P C C$ when $t=0 s$. At $t=2 s, D G_{3}$ is been disconnected by switch off swith 1 shown in Figure 1. Analyses on the effect of the disconnection and 
reconnection of $\mathrm{DG}_{3}$ for power sharing accuracy cause to the neighbouring DGs with the scheme is shown in Figures 9(a) and (b). Simulation results show that, the power sharing accuracy can be attained when $\mathrm{DG}_{3}$ is disconnected with the same load value. During this time the $\mathrm{DG}_{1}$ and $\mathrm{DG}_{2}$ starts to increase the power near to rated value and also it can be seen the real power and reactive power have been shared equally. Therefore, it is conculuded that when one of the DG is disconnected from the system orther DGs can equally share the load and power sharing accuracy is not affected in the parallel connected DGs $\mathrm{mG}$ system. So, from proposed cotrol technique the disconnection of DG unit does not affect the power sharing accuracy of the neighbouring DGs.

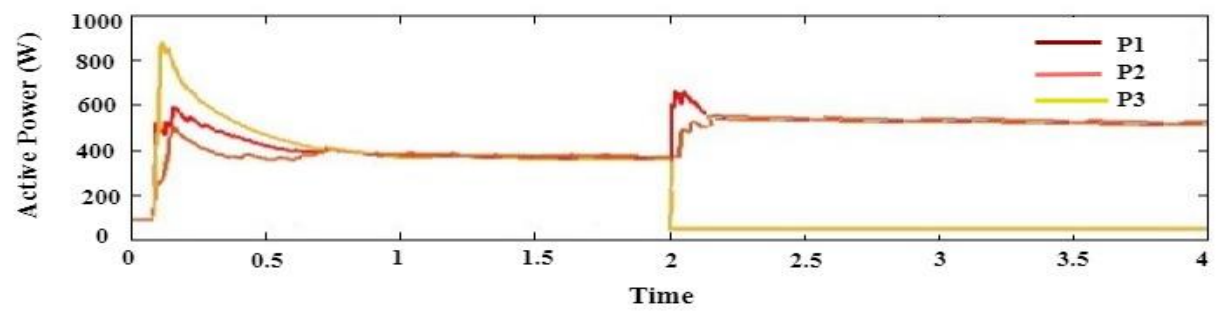

(a) Active power

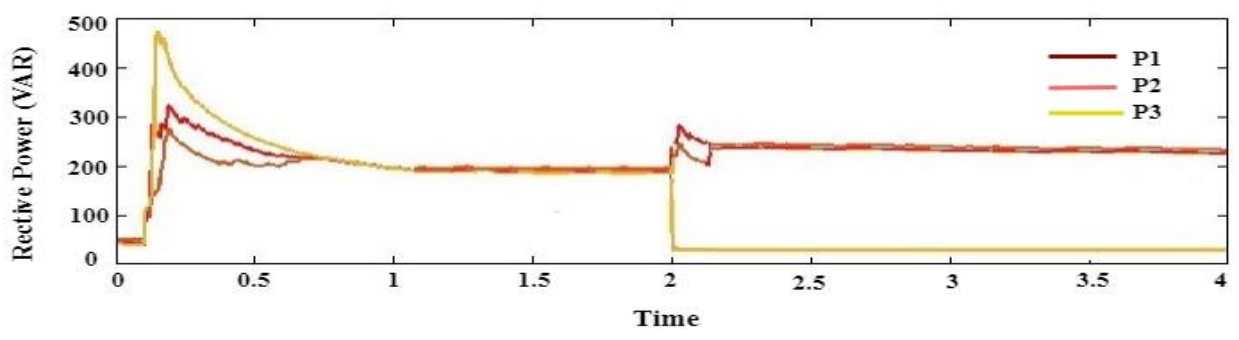

(b) Reactive power

Figure 9. Disconeteing and reconecting influence on the power sharing performance of neighboring DGs

\section{CONCLUSION}

Reactive power sharing accuracy in case of load variations has been explained in this paper. The compensation scheme makes the control scheme more affective in combination of the P- $\omega$ droop control. In this power droop topology, at first the imprecise active power generated and which make it easy to calculate the reactive power sharing error. Reactive power sharing errors are reduced by PI controller which helps modifying the values of the conventional voltage droop curve with the help of changing the values of the slope of the y-intercept. Simulation result shows that by implementing locally recognition-based power correction scheme (proposed control technique) more accurately active and reactive powers are shared. Moreover, from the proposed control technique the system stability and reliability are also guaranteed in the suggested control scheme.

\section{ACKNOWLEDGEMENTS}

The authors would like to express their deepest appreciation to all that have contributed to the success of this research, especially for the fundings from Research Fund E15501, Research Management Centre, Universiti Tun Hussein Onn Malyasia and special thanks to Advanced Control on Power Converters Team, FKEE.

\section{REFERENCES}

[1] F. R. Badal, P. Das, S. K. Sarker, and S. K. Das, "A survey on control issues in renewable energy integration and microgrid," Protection and Control of Modern Power Systems, vol. 4, no. 8, 2019.

[2] H. P. de Moraes, "Argüição de Descumprimento de Preceito Fundamental," Revista da EMERJ, vol. 4, no. 13, pp. 135-148, 2001.

[3] J. Xu, X. Cao, and Z. Hao, "A Droop Control Strategy Based on Synchronous Rectifier to Modulate the Frequency and Voltage in AC Microgrid," 2019 22nd International Conference on Electrical Machines and Systems (ICEMS), Harbin, China, pp. 1-5, 2019.

[4] L. Lei, M. A. Elgendy, N. Wade, and S. Ethni, "Power sharing between parallel inverters by using droop control with a secondary control loop," 2019 IEEE 10th International Symposium on Power Electronics for Distributed Generation Systems (PEDG), Xi'an, China, pp. 653-658, 2019. 
[5] H. Han, X. Hou, J. Yang, J. Wu, M. Su, and J. M. Guerrero, "Review of Power Sharing Control Strategies for Islanding Operation of AC Microgrids," in IEEE Transactions on Smart Grid, vol. 7, no. 1, pp. 200-215, 2016.

[6] D. E. Olivares, et al., "Trends in microgrid control," in IEEE Transactions on Smart Grid, vol. 5, no. 4, pp. 1905-1919, 2014.

[7] X. Hou, Y. Sun, W. Yuan, H. Han, C. Zhong, and J. M. Guerrero, "Conventional P- $\omega /$ Q-V droop control in highly resistive line of low-voltage converter-based AC microgrid," Energies, vol. 9, no. 11, 2016.

[8] J. Zhou, M. Tsai, and P. Cheng, "Consensus-based Cooperative Droop Control for Accurate Reactive Power Sharing in Islanded AC Microgrid," in IEEE Journal of Emerging and Selected Topics in Power Electronics, vol. 8, no. 2, pp. 1108-1116, June 2020.

[9] H.-J. Yoo, T.-T. Nguyen, and H.-M. Kim, "Consensus-based Distributed Coordination Control of Hybrid AC/DC Microgrids," in IEEE Transactions on Sustainable Energy, vol. 11, no. 2, pp. 629-639, April 2020.

[10] C. K. Sao, S. Member, and P. W. Lehn, "Voltage Source Converters," IEEE Trans. Power Deliv., vol. 20, no. 2, pp. 1009-1016, 2005.

[11] D. I. Brandao, W. M. Ferreira, A. M. S. Alonso, E. Tedeschi, and F. P. Marafao, "Optimal Multiobjective Control of Low-Voltage AC Microgrids: Power Flow Regulation and Compensation of Reactive Power and Unbalance," in IEEE Transactions on Smart Grid, vol. 11, no. 2, pp. 1239-1252, 2020.

[12] Y. Qi, J. Fang, and Y. Tang, "Utilizing the Dead-time Effect to Achieve Decentralized Reactive Power Sharing in Islanded AC Microgrids," in IEEE Journal of Emerging and Selected Topics in Power Electronics, 2019.

[13] Y. W. Li and C. N. Kao, "An accurate power control strategy for power-electronics-interfaced distributed generation units operating in a low-voltage multibus microgrid," in IEEE Transactions on Power Electronics, vol. 24, no. 12 , pp. 2977-2988, 2009.

[14] A. M. Dos Santos Alonso, D. I. Brandao, F. P. Marafao, and E. Tedeschi, "Coordinated control of parallel power conditioners synthesizing resistive loads in single-phase AC microgrids," 201921 st European Conference on Power Electronics and Applications (EPE'19 ECCE Europe), Genova, Italy, pp. P.1-P.9, 2019.

[15] A. Rosini, M. Minetti, G. B. Denegri, and M. Invernizzi, "Reactive Power Sharing Analysis in Islanded AC Microgrids," 2019 IEEE International Conference on Environment and Electrical Engineering and 2019 IEEE Industrial and Commercial Power Systems Europe (EEEIC/I\&CPS Europe), Genova, Italy, pp. 1-6, 2019.

[16] E. Rokrok and M. E. H. Golshan, "Adaptive voltage droop scheme for voltage source converters in an islanded multibus microgrid," in IET Generation, Transmission \& Distribution, vol. 4, no. 5, pp. 562-578, 2010.

[17] Y. Liu et al., "A reactive power-voltage control strategy of an AC microgrid based on adaptive virtual impedance," Energies, vol. 12, no. 16, pp. 3057-3072, 2019.

[18] Y. Hu, X. Wang, Y. Peng, J. Xiang, and W. Wei, "Distributed Finite-Time Secondary Control for DC Microgrids with Virtual Impedance Arrangement,” IEEE Access, vol. 7, pp. 57060-57068, 2019.

[19] W. Yao, M. Chen, J. Matas, J. M. Guerrero, and Z. M. Qian, "Design and analysis of the droop control method for parallel inverters considering the impact of the complex impedance on the power sharing," in IEEE Transactions on Industrial Electronics, vol. 58, no. 2, pp. 576-588, 2011.

[20] S. M. Mohiuddin and J. Qi, "Droop-Free Distributed Control for AC Microgrids with Precisely Regulated Voltage Variance and Admissible Voltage Profile Guarantees," in IEEE Transactions on Smart Grid, vol. 11, no. 3, pp. 1956-1967, 2020.

[21] Q. C. Zhong, "Robust droop controller for accurate proportional load sharing among inverters operated in parallel," in IEEE Transactions on Industrial Electronics, vol. 60, no. 4, pp. 1281-1290, 2013.

[22] E. E. Pompodakis, G. C. Kryonidis, and M. C. Alexiadis, "A Comprehensive load Flow Approach for GridConnected and Islanded AC Microgrids," in IEEE Transactions on Power Systems, vol. 35, no. 2, pp. 1143-1155, 2020.

[23] H. Han, Y. Liu, Y. Sun, M. Su, and J. M. Guerrero, "An improved droop control strategy for reactive power sharing in islanded microgrid," in IEEE Transactions on Power Electronics, vol. 30, no. 6, pp. 3133-3141, 2015.

[24] Y. Khayat, et al., "Estimation-based consensus approach for decentralized frequency control of AC microgrids," 201921st European Conference on Power Electronics and Applications (EPE '19 ECCE Europe), Genova, Italy, pp. 1-8, 2019.

[25] A. Gandhi, "Reactive Power Sharing Control Strategy Based on Droop Control in Islanded Microgrid," International Journal for Modern Trends in Science and Technology (IJMTST), vol. 2, no. 7, pp. 160-163, 2016.

[26] J. He and Y. W. Li, "An enhanced microgrid load demand sharing strategy," in IEEE Transactions on Power Electronics, vol. 27, no. 9, pp. 3984-3995, 2012.

[27] X. Meng, N. Zhou, Q. Wang, and J. M. Guerrero, “A Nonlinear, Bounded and Lipchitz Continuous Distributed Active Power Sharing Control Method for Islanded AC Microgrids," IEEE Access, vol. 7, pp. 36843-36853, 2019.

[28] J. M. Guerrero, J. M. Alcala, J. Miret, L. García De Vicuña, J. Matas, and M. Castilla, "Output Impedance Design of Parallel-Connected UPS Inverters With Wireless Load-Sharing Control," in IEEE Transactions on Industrial Electronics, vol. 52, no. 4, pp. 1126-1135, 2005.

[29] M. Fusero, A. Tuckey, A. Rosini, P. Serra, R. Procopio, and A. Bonfiglio, "A comprehensive inverter-bess primary control for AC microgrids," Energies, vol. 12, no. 20, 2019.

[30] N. Alwaz, S. Raza, S. Ali, M. K. L. Bhatti, and S. Zahra, "Harmonic Power Sharing and Power Quality Improvement of Droop Controller Based Low Voltage Islanded Microgrid," 2019 International Symposium on Recent Advances in Electrical Engineering (RAEE), Islamabad, Pakistan, pp. 1-6, 2019.

[31] J. M. Guerrero, J. C. Vasquez, J. Matas, L. G. De Vicuña, and M. Castilla, "Hierarchical control of droopcontrolled AC and DC microgrids-A general approach toward standardization," in IEEE Transactions on Industrial Electronics, vol. 58, no. 1, pp. 158-172, 2011. 